
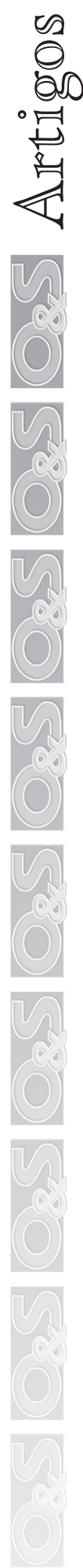


\title{
COMPETEN $\mathbb{N}$ CIAS GERENCIAIS NO CONTEXTO \\ INTERNACIONAL: POSSIVEIS CONTRIBUICGÖES DE CURSOS SUPERIORES BRASILEIROS DE $A D \mathbb{M} I \mathbb{N} I S T R A C \widetilde{A} O$
}

\author{
Adriana de Faria e Sousa* \\ Valdir Machado Valadão Júnior**
}

Restrino

\begin{abstract}
Oserase
objetivo deste estudo foi identificar e analisar as competências gerenciais contempladas em ementas de disciplinas dos cursos superiores de Administração que, direta ou indiretamente, contribuem para o desenvolvimento de competências relevantes ao gestor que pretende assumir designações internacionais. Selecionou-se uma amostra de 24 instituições de ensino superior (IES) a partir dos seguintes critérios: (1) resultados do Exame Nacional de Desempenho de Estudantes (ENADE) e avaliação realizada pelo Ministério da Educação e Cultura (MEC); e (2) cursos participantes do Projeto de Pesquisa Pró-Administração, ligados à Universidade Federal de Uberlândia (UFU). Para analisar as ementas dos cursos de Administração dessas IES, utilizou-se a técnica de análise de conteúdo clássica. A interpretação dos dados foi orientada por parâmetros que tiveram como base os resultados de levantamento junto a brasileiros que trabalham no exterior (SOUSA et al., 2010) e os estudos de Echeveste e outros, (1999) e McCall e Hollenbeck (2003). Foram avaliadas 1.324 ementas, tendo sido identificadas aderências às competências propostas em 622 ( $46,97 \%$ do corpus). Com maior frequência, foram encontradas: visão estratégica, capacidade de decisão, capacidade de correlação de fatos com importância para a empresa e capacidade para tratar com culturas diversas.
\end{abstract}

Palavras-chave: Competências. Competências Gerenciais. Gestor global. Ementas. Cursos de Administração.

Abstrealt

11 he objective of this study was to identify and analyze the managerial competencies covered in menus disciplines of higher education courses of Business Management, that directly or indirectly contribute to the development of relevant skills to the manager who wants to take international assignments. It was selected a sample of 24 institutions of higher education, based on the following criteria: (1) results of National Performance of Students (Enade) and on-site evaluation conducted by the Ministry of Education and Culture (MEC); (2) courses included in a program called

\footnotetext{
*Mestre em Administração, Universidade Federal de Uberlândia (UFU).

Professora do curso de Relações Públicas da Escola Superior de Administração, Marketing e Comunicação (ESAMC) - Uberlândia.

E-mail: adriana.sousa@esamc.br

**Doutor em Engenharia de Produção pela Universidade Federal de Santa Catarina (UFSC). Professor associado da Universidade Federal de Uberlândia (UFU) e Coordenador do Programa de Pós- graduação em Administração da Faculdade de Gestão e Negócios (UFU).

Email: valdirjr@ufu.br
} 
"Pró Administração", connected to Universidade Federal de Uberlândia. There was used classical content analysis, based on the descriptions of these courses, developed from parameters that were based on the results of survey among Brazilian managers working abroad (Sousa et al., 2010) and studies of Echeveste and others (1999) and McCall and Hollenbeck (2003). 1324 courses description have been evaluated, and in 622 (46.97\% of the corpus) it was possible to identify adhesions to the proposed competencies. With greater frequency, were found: strategic vision, decision-making ability, capacity of correlation between events of importance to the company and ability to deal with different cultures.

Key-Words: Competences. Managerial competencies. Global manager. Course description. Business Administration course. 
atuação de organizações brasileiras no mercado global, bem como de empresas internacionais no Brasil, representa um fenômeno crescente (FUNDAÇÃO DOM CABRAL, 2009) e vem sendo foco de estudos acadêmicos nos últimos anos, em especial, sobre a temática da expatriação. (BUENO; DOMINGUES; DEL CORSO, 2004; HOMEM; DELLAGNELLO, 2006; LESSA et al., 2008)

Autores brasileiros e estrangeiros avaliaram o assunto sob enfoques que transitam dos processos de adaptação - presentes nos estudos iniciais (BLACK; MENDENHALL; ODDOU, 1991; JOLLY, 1996) - para outras abordagens, como o desenvolvimento das competências necessárias a este profissional que se propõe a praticar a gestão em contexto multicultural. (CALIGIURI; DI SANTO, 2001; ECHEVESTE et al., 1999; McCAUGHEY; BRUNING, 2005; PEREIRA; PIMENTEL; KATO, 2004)

Considerando o reflexo desse contexto na formação do administrador brasileiro que tenha aspirações a desenvolver uma carreira corporativa no exterior, o presente artigo tem como objetivo identificar e analisar as competências gerenciais contempladas em ementas de disciplinas dos cursos superiores de Administração que, direta ou indiretamente, contribuem para o desenvolvimento de competências relevantes para o gestor que pretende assumir designações internacionais.

Sabe-se que competências gerenciais são construídas a partir de experiências cognitivas e atitudinais. (CHEETHAM; CHIVERS, 1998; LE BOTERF, 2003; SEBBEN, 2009; ZARIFIAN, 2008) As primeiras, parcialmente, resultam da formação acadêmica. Closs e Antonello (2008) defendem que existem diferentes formas de aprendizado de processos gerenciais, que passam também pela educação formal e informal. Mintzberg e Gosling (2003) dizem que "embora administradores não possam ser criados em uma sala de aula, é nesse local que muitos administradores atuantes podem melhorar profundamente suas capacidades". (MINTZBERG; GOSLING, 2003, p. 31)

É sobre esse contexto, especificamente a associação entre uma atuação internacional e os cursos de graduação em IES brasileiras, que o presente artigo propõe lançar reflexões adicionais a estudos anteriores focados em designações internacionais. Trata-se de um recorte a Sousa (2011), que teve como propósito inicial entender as lições aprendidas por gestores brasileiros que viviam e trabalhavam no exterior, a partir da pesquisa de McCall e Hollenbeck (2003). Nesse estudo, detectou-se que parte significativa dos entrevistados possuía graduação em Administração.

Esse recorte dos dados alterou o questionamento inicial, direcionando-o a novas possibilidades de investigação. Voltou-se, então, para avaliar se as lições identificadas inicialmente, traduzidas em competências - de acordo com os modelos propostos por McCall e Hollenbeck (2003) e Echeveste e outros. (1999) - poderiam, de alguma forma, ser relacionadas às competências previstas para serem desenvolvidas em cursos superiores de Administração, de acordo com o que preconizam as Diretrizes Curriculares Nacionais (DCN).

Esse breve resgate do processo de construção da pesquisa se fez necessário para a apresentação da pergunta norteadora do presente estudo: quais competências gerenciais as ementas das disciplinas dos cursos de Administração têm contemplado? Em outras palavras, em que medida as ementas dos cursos de Administração têm privilegiado a formação de competências para aqueles alunos que pretendem atuar em contexto internacional?

O núcleo teórico deste estudo é formado por duas abordagens: (1) perfil e competências necessárias ao gestor que pretende atuar globalmente; e (2) desenvolvimento de competências no ensino superior, com ênfase ao curso de Administração e suas DCN. Busca-se aqui abrir espaço sobre uma discussão alinhada às demandas do mercado e passível de críticas quanto ao papel do ensino superior brasileiro. A dualidade emerge porque ainda prevalece a dicotomia mercado versus formação de cidadãos críticos e autônomos. (RAMOS, 2001)

$\mathrm{O}$ artigo estrutura-se em quatro partes. Na primeira, uma breve contextualização do tema expatriação e a apresentação das características do gestor internacional, de acordo com o que foi identificado na literatura acerca de seu perfil e competências 
necessárias para o papel profissional. Em seguida, será feita uma discussão acerca de competências e seu relacionamento com a pedagogia, bem como uma apresentação das DCN para os cursos superiores de Administração. Posteriormente, serão demonstrados os aspectos metodológicos e a análise dos resultados.

\section{Carracteristicas do Gestor Globar}

Desde a década de 1980, realizaram-se diferentes estudos acerca do tema expatriação. É possível agrupá-los a partir de características em comum: (1) foco na identificação do profissional adequado para ocupar designações internacionais (CALIGIURI; DI SANTO, 2001; McCAUGHEY; BRUNING, 2005) - que se mantém muito mais nas competências técnicas do que nas habilidades de relacionamento e adequação, incluindo a familiar; (2) importância dos aspectos culturais de cada país, que influenciam na adaptação do profissional e sua família ao novo contexto (BLACK, MENDENHALL; ODDOU, 1991; JOLLY, 1996; PEREIRA, PIMENTEL; KATO, 2004); (3) busca pela definição de um perfil adequado à gestão em contexto intercultural (BLACK; GREGERSEN, 1999; GONDIM et al., 2009; SEBBEN, 2009); e (4) fatores de sucesso e fracasso na expatriação (PEREIRA; PIMENTEL; KATO, 2004). Os autores apontam, de maneira geral, para a pouca preocupação das organizações com relação ao período de ajustamento do profissional ao novo contexto de trabalho, um dos principais componentes que leva à permanência (ou não) no exterior.

De acordo com pesquisa desenvolvida pela Brookfield Global Relocation Service, publicada em 2010, o preenchimento de lacunas de competências técnicas e gerenciais foram os principais motivos para expatriações em 120 empresas pesquisadas. Outro estudo, realizado pela Sociedade Brasileira de Estudos de Empresas Transnacionais e da Globalização Econômica (SOCIEDADE..., 2007), apontou a ausência de conhecimentos gerenciais para se internacionalizar e o baixo conhecimento de idiomas como barreiras à internacionalização de empresas brasileiras.

$\mathrm{Na}$ contemporaneidade, o profissional que atua no contexto internacional é denominado, principalmente, gestor global (MCCALL; HOLLENBECK, 2003) ou gestor cosmopolita. (BUENO; DOMINGUES; DEL CORSO, 2004; HOMEM; DELLAGNELLO, 2006; KANTER, 1996; SELMER, 2001; TUNG, 1998) Seu perfil assemelha-se ao de um "super" profissional dotado de características e competências que podem ser desenvolvidas em diferentes contextos, entre eles o acadêmico. Sousa e outros (2010) descreveram esse perfil a partir dos conceitos apresentados por Bartlett e Ghoshal (1992), Hoelchlin, 1995 (apud LESSA et al., 2008), Black e Gregersen (1999), Oderich e Lopes (2001), McCall e Hollenbeck (2003), Homem e Dellagnello (2006), Lessa e outros (2008) e Gondim e outros (2009).

Echeveste e colaboradores (1999) identificaram um grupo de competências que foi adotado para a elaboração dos parâmetros que nortearam o presente estudo. De acordo com os autores, são eles: dimensionamento do tempo, coordenação de trabalhos em equipe, gerenciamento da inovação, integração das diversas áreas funcionais, capacidade para tratar com culturas diversas, antecipação de ameaças e oportunidades, capacidade de negociação, visão estratégica, capacidade de delegação, capacidade de decisão, habilidade interpessoal, capacidade de liderança, agilidade, autogerenciamento, resolvedor de problemas, foco no resultado, administrador de conflito, desenvolvedor de pessoas, capacidade de viabilizar/implementar ideias e capacidade de correlação de fatos com repercussões para a empresa.

Diferentes autores corroboram aspectos contidos na lista de competências identificada por Echeveste e outros. (1999). Gondin e colaboradores (2009) ressaltam que o profissional que pretente atuar internacionalmente deve possuir visão estratégica, o que é considerado por Fleury e Fleury (2001) como um dos sete saberes ligados ao conceito de competência. Le Boterf (2003, p. 92) classifica a capacidade de decisão como um "saber agir e reagir com pertinência", ressaltando a habilidade de se escolher na urgência e saber decidir. Para Black e Gregersen (1999), o gestor global precisa ser 
capaz de correlacionar os fatos e acontecimentos dos ambientes interno e externo, o que vai influenciar a qualidade das decisões.

A capacidade de estabelecer relacionamento produtivo com profissionais de diferentes culturas é uma das características mais apontadas pelos autores pesquisados. (BLACK; GREGERSEN, 1999; GONDIN et al., 2009; HOMEM; DELLAGNELLO, 2006; LESSA et al., 2008; MCCALL; HOLLENBECK, 2003) Fischer e outros (2009) descrevem a competência intercultural como relevante para abrir canais de diálogo e resolução de conflitos. Sebben (2009) aborda a necessidade de uma educação intercultural que capacite o profissional para conviver com as diferenças, uma vez que a mobilidade é uma realidade cada vez mais presente no ambiente organizacional. A autora aponta, ainda, a importância do que chama de competência comportamental, que indica características relacionadas a gostar de pessoas, liderança e capacidade de conectar-se, como fundamentais à gestão no contexto internacional.

Adaptar-se rapidamente a um cenário em transformação é outra demanda para o profissional que pretende atuar no exterior. Homem e Dellagnello (2006) e Hoelchlin (1995, apud LESSA et al., 2008) tratam da importância do gestor em adaptar-se às mudanças que ocorrem de maneira cada vez mais veloz. Cheetam e Chivers (1998) apontam a capacidade de administrar o próprio tempo como uma competência funcional, diretamente ligada ao papel que o profissional exerce ou virá a exercer. Compartilhar responsabilidades com a equipe e saber relacionar-se em diferentes níveis (hierárquicos, profissionais e pessoalmente) são características identificadas por Hoelchlin (1995 apud LESSA et al., 2008), McCall e Hollenbeck (2003) e Homem e Dellagnello (2006).

Em estudo desenvolvido por Sousa (2011), essas competências foram relacionadas aos resultados de um levantamento feito junto a 195 gestores brasileiros que trabalhavam no exterior. Identificou-se um conjunto de lições aprendidas por esses profissionais, com base nas conclusões do livro de McCall e Hollenbeck (2003) e cinco grupos de aprendizados que emergiram da análise fatorial dos dados (gestão de negócios, de pessoas, de stakeholders, relações hierárquicas, idioma e cultura). Cada um deles, bem como as competências correlatas, será discutido posteriormente no presente artigo.

A seguir, apresentam-se algumas considerações acerca do tema competências profissionais.

\section{Comperências $\mathbb{P}_{10}$ firsionaris}

Atuar profissionalmente em um país diferente do seu de origem demanda do gestor conhecimentos e competências pessoais e profissionais de alto nível, adquiridas ao longo de sua formação, de sua carreira ou por meio de designações internacionais. O profissional aprende enquanto acumula experiências no mercado, mas também enquanto estuda, lê, interage com colegas do país de origem e do exterior e se expõe aos relacionamentos multiculturais.

Em busca de um conceito que contemplasse diferentes perspectivas, a definição de competências tem sido alvo de muitos estudos acadêmicos. (DUTRA, 2004; FLEURY; FLEURY, 2001; LE BOTERF, 2003; RUAS, 2005; ZARIFIAN, 2008) O ponto em comum entre os autores é a apresentação da composição clássica entre conhecimentos, habilidades e atitudes para a realização de determinadas atividades profissionais que vão além do conhecimento técnico e operacional necessários para a execução de tarefas repetitivas.

De acordo com Le Boterf (2003), a formação do trabalhador para a execução de tarefas cada vez mais especializadas requer a busca de conhecimentos técnicos e específicos, a partir dos quais seria possível lidar com a complexidade do mundo do trabalho. Nesse contexto, mais do que estar qualificado para a operação de rotinas repetitivas, o mercado passou a exigir do trabalhador uma postura ativa para a resolução de problemas e busca de alternativas de ação diante de situações imprevistas, sempre com vistas à otimização da produção. 
Deluiz (2004) relembra que é nesse contexto de mudanças no mundo do trabalho que a discussão acerca de educação profissional ganha espaço na agenda de educadores e corporações. O desenvolvimento dos conhecimentos exigidos para uma atuação cada vez mais especializada passa pelos bancos escolares, dentro de uma perspectiva que atenda à "dupla dimensão dos objetivos educacionais: preparar o profissional competente e o cidadão socialmente responsável, o sujeito-político comprometido com o bem-estar coletivo". (DELUIZ, 2004) Paiva e Melo (2008) também abordam a dimensão política em seu estudo a respeito de competências.

Para Dutra (2004), competências são "o conjunto de conhecimentos, atitudes e habilidades necessárias para que a pessoa desenvolva suas atribuições e responsabilidades". (DUTRA, 2004, p. 28) São os recursos que os indivíduos buscam internamente para entregar resultados esperados pela organização ou pelos públicos cujos interesses se comprometeram a atender.

O conceito proposto por Fleury e Fleury (2001) é retomado por diferentes autores. (BASTOS; MONTEIRO JÚNIOR, 2009; PAIVA; MELO, 2008) Eles definem competência como uma combinação entre as proposições clássicas de Le Boterf (2003) e Zarifian (2008), sendo possível alinhá-la às características que se exigem do gestor internacional, ou seja, ele precisa colocar seus conhecimentos com o objetivo de estabelecer relações produtivas entre as organizações e suas subsidiárias espalhadas em diferentes países e continentes. Nesses espaços, falam-se línguas diferentes, vivem-se culturas nacionais e organizacionais distintas e existe um modo particular e específico de gestão.

Fischer e outros (2009, p. 2) apresentam uma definição específica para a competência intercultural, seria aquela que "corresponde à capacidade do gestor de reconhecer e compreender a existência de crenças e valores próprios de cada cultura, assim como estabelecer diálogos produtivos com a população local, além de dirimir conflitos resultantes de possíveis choques interculturais". O gestor tem que colocar em prática suas competências em administração de negócios internacionais, desenvolvidas a partir de sua experiência pessoal, acadêmica, social e profissional.

No caso do gestor internacional, o reconhecimento pode ser a própria designação internacional ou a superação de desafios específicos da gestão em contextos globais. Para este estudo, optou-se por Zarifian (2008), uma vez que se trata da importância do desenvolvimento de conhecimentos, habilidades e atitudes que são colocadas em prática em determinadas situações e contextos. Embora as competências tenham sido adquiridas em diferentes momentos ao longo da carreira, inclusive no âmbito acadêmico, passam a fazer sentido quando de sua utilização. Combinada à proposição de Ruas (2005), segundo a qual não se é competente antes da hora, ou seja, do momento necessário para a mobilização das competências em situações de trabalho, entende-se aqui que as competências são o arsenal cognitivo, de procedimentos e atitudes ao qual o gestor internacional irá recorrer diante da complexidade das situações reais de trabalho.

De modo semelhante, as competências gerenciais se desenvolvem dentro de determinados contextos e ambientes. Segundo Closs e Antonello (2008), o processo de aprendizagem acontece na interação entre os indivíduos, configurando-se como uma atividade social que ocorre além das fronteiras da mente do aprendiz. No caso do desenvolvimento gerencial, a relação é entre o gestor e os múltiplos stakeholders. Em ambientes internacionais, entram em cena também os aspectos culturais, conforme aponta Queiroz (1988), citado pelos primeiros.

Lyles (2001, p. 287) afirma que os expatriados "são veículos eficazes para a aquisição de conhecimento [...] em razão de seus relacionamentos e capacidades de conexão". A internacionalização de empresas é motivada, em parte, pela capacidade das pessoas e organizações de aprender. (BARTLETT; GHOSHAL, 1992) Sebben (2009) apresenta uma classificação das competências necessárias a quem pretende trabalhar no contexto multicultural: afetivas, sociocognitivas e comportamentais. Para a autora, é necessário que o gestor aprenda a respeito de diversidade cultural e tenha aptidão para conviver em ambientes diversificados. 
Ressalta-se que um dos ambientes onde essas competências podem ser desenvolvidas é a academia. Uma vez que o foco deste estudo é verificar quais competências gerenciais as ementas das disciplinas dos cursos de Administração têm contemplado, apresentam-se, a seguir, aspectos relacionados às DCN desses cursos.

\section{Direrrizes Crrrricurlares Naciornaris - DCN}

No Brasil, os primeiros cursos de Administração surgiram, formalmente, entre os anos 1950 e 1960, a partir da necessidade de desenvolver administradores para o preenchimento de quadros nas empresas públicas e privadas. No final dos anos 1960, a profissão foi regulamentada com o estabelecimento de um currículo mínimo a ser cumprido. Na década de 1970, houve um crescimento acelerado no número de cursos, reflexo daquele momento econômico. Em meados dos anos 1990, tiveram início discussões para a atualização do currículo mínimo, vigente por mais de 20 anos. (NICOLINI, 2003)

Em 2004, após várias discussões e alterações na legislação relativa ao ensino superior brasileiro, foram estabelecidas as DCN para os cursos de Administração. Conforme o documento, os cursos devem ser estruturados de maneira a incluir conteúdos que contemplem "A inter-relação entre a realidade nacional e internacional segundo uma perspectiva histórica e contextualizada de sua aplicabilidade no âmbito das organizações e do meio". (BRASIL, 2005, grifo nosso) Para cumprir esse propósito, os cursos devem utilizar tecnologias e oferecer os seguintes conteúdos: formação básica, formação profissional, estudos quantitativos e suas tecnologias e formação complementar.

Nunes e Barbosa (2003) acreditam que as DCN contribuíram para a flexibilização dos currículos dos cursos de Administração pelas IES, permitindo que elas adequassem seus conteúdos às demandas sociais e aos avanços científícos e tecnológicos com maior autonomia. Embora nem sempre estejam presentes no nome das disciplinas de maneira explícita (do ponto de vista semântico), as diretrizes apontam para a preocupação em formar um profissional alinhado às demandas de seu tempo, preparado para "enfrentar os desafios das rápidas mudanças na sociedade". (NUNES; BARBOSA, 2003, p. 5), bem como dotado de "flexibilidade intelectual e adaptabilidade contextualizada no trato de situações diversas, presentes ou emergentes". (BRASIL, 2005) Esses aspectos encontram-se listados entre as competências que precisam ser desenvolvidas pelo profissional com atuação global, apresentados anteriormente.

Em relação às competências e habilidades necessárias ao futuro profissional, as DCN estabelecem que o aluno deve desenvolver, no mínimo: (1) o pensamento estratégico, por meio do aprendizado acerca de resolução de problemas e tomada de decisão; (2) a expressão e comunicação compatíveis à atividade, para facilitar negociações e relacionamentos grupais; (3) gerenciar a produção de maneira reflexiva e crítica; (4) raciocínio lógico, crítico e analítico a ser utilizado em contextos de diferentes complexidades; (5) iniciativa e criatividade; (6) capacidade de transferir conhecimentos; (7) capacidade de elaborar projetos; e (8) capacidade de oferecer consultorias.

De acordo com Brito (2008), as competências específicas se refletem nos projetos pedagógicos de forma a garantir ao egresso a posse de um nível de conhecimentos básicos sobre o campo de atuação escolhido, bem como a capacidade para colocá-los em prática em diferentes contextos. Diante disso, quando se pensa nas características necessárias ao gestor global, algumas das competências desenvolvidas nos cursos brasileiros de graduação em Administração podem ser acionadas quando necessárias.

Para Nicolini (2002), o modelo proposto pelas DCN para os cursos de Administração está alinhado aos desafios do administrador na contemporaneidade, mas é importante não se perder de vista a forma como, realmente, os projetos pedagógicos se concretizam. Sob uma abordagem crítica, o autor questiona se a academia está efetivamente contribuindo para desenvolver competências que levem o indivíduo à ação, ou se estaria meramente reproduzindo conteúdos dentro de um esquema que repete a existência dos currículos mínimos obrigatórios. Para o autor, essa transição 
exigiria das IES uma postura de abertura à mudança e de práticas de gestão alinhadas às transformações do mundo do trabalho.

Apresentados os conceitos que sustentam este artigo, passa-se aos aspectos metodológicos da pesquisa empírica realizada.

\section{Aspectos Metodológicos}

Este estudo parte das competências do administrador brasileiro que pretende assumir designações internacionais, em seus diferentes formatos, e apresenta o seguinte questionamento: quais competências gerenciais as ementas das disciplinas dos cursos de Administração têm contemplado? Na busca por respostas, estabeleceu-se, como objetivo, identificar e analisar as competências gerenciais contempladas em ementas de disciplinas dos cursos superiores de Administração que, direta ou indiretamente, contribuem para o desenvolvimento de competências relevantes para o gestor que pretende assumir designações internacionais.

Com base nos dados disponíveis para pesquisa, delimitou-se: 1) escolher os cursos de administração avaliados no ENADE com nota cinco (máxima); e 2) entre todas as informações disponíveis acerca dos cursos (projeto pedagógico, programa do curso, descrição do curso e ementário), definiu-se que seriam estudadas as ementas, uma vez que feita uma pesquisa inicial, foi possível ter acesso a esses dados na maioria dos cursos selecionados.

Ressalta-se aqui o entendimento de que o ementário representa uma das possibilidades de análise, mas que uma compreensão mais ampla acerca das competências desenvolvidas pelo profissional brasileiro que trabalha no exterior passaria por entrevistas com profissionais egressos de cursos de Administração que, efetivamente, vivenciam essa realidade, podendo-se ainda abordar suas equipes de trabalho, líderes e liderados. Vale enfatizar a compreensão de que os conhecimentos adquiridos em programas de graduação são apenas uma parte do processo de aquisição e desenvolvimento de competências, que soma-se a aspectos como experiências de vida, vivências profissionais, situações concretas no mundo dos negócios, entre outros.

Comstrurção dlos parrânetros de arnålise

Para a construção dos parâmetros para análise das ementas dos cursos de graduação em Administração, optou-se por uma reunião das contribuições de Sousa (2011), Sousa e outros (2010) e Echeveste e outros (1999). Nos estudos de Sousa (2011) e Sousa e outros (2010), foram identificados aprendizados e lições do gestor global, os quais, após análise fatorial, permitiram a identificação de cinco variáveis de análise, adotadas como ponto de partida para este estudo. São elas:

(1) gestão de pessoas: trata de questões ligadas ao relacionamento do gestor com sua equipe de trabalho, abordando aspectos como recrutamento e seleção, formação de equipes, credibilidade e motivação;

(2) idioma e cultura: conhecimento de língua estrangeira e de aspectos da cultura de outros povos que influenciam no processo de gestão;

(3) relações hierárquicas: relacionamentos que acontecem entre pares, líderes e liderados em diferentes países;

(4) gestão de stakeholders: relacionamentos necessários com sindicados, mídia, governos e política dos países;

(5) gestão de negócios: aspectos relacionados à administração propriamente

dita. 
A cada uma dessas variáveis foram relacionadas as competências identificadas por Echeveste e outros (1999), citadas anteriormente. Para isso, utilizou-se a técnica de análise de conteúdo. (BAUER; GASKELL, 2002) Desse processo resultaram os parâmetros para análise, apresentados no Quadro 1.

\section{Quadro 1 - Parâmetros para análise das ementas dos cursos de graduação em Administração}

\begin{tabular}{|c|c|c|c|c|c|c|}
\hline & Competências & $\begin{array}{l}\text { Gestão de } \\
\text { Pessoas }\end{array}$ & $\begin{array}{l}\text { Idioma e } \\
\text { Cultura }\end{array}$ & $\begin{array}{l}\text { Relações } \\
\text { Hierárquicas }\end{array}$ & $\begin{array}{l}\text { Gestão de } \\
\text { Stakeholders }\end{array}$ & $\begin{array}{l}\text { Gestão de } \\
\text { Negócios }\end{array}$ \\
\hline 1 & $\begin{array}{l}\text { Administrador de } \\
\text { conflito }\end{array}$ & & & & & \\
\hline 2 & Agilidade & & & & & \\
\hline 3 & $\begin{array}{l}\text { Capacidade de } \\
\text { decisão }\end{array}$ & & & & & \\
\hline 4 & $\begin{array}{l}\text { Capacidade de } \\
\text { delegação }\end{array}$ & & & & & \\
\hline 5 & $\begin{array}{l}\text { Capacidade de } \\
\text { liderança }\end{array}$ & & & & & \\
\hline 6 & $\begin{array}{l}\text { Capacidade de } \\
\text { negociação }\end{array}$ & & & & & \\
\hline 7 & $\begin{array}{l}\text { Coordenação } \\
\text { de trabalho em } \\
\text { equipe }\end{array}$ & & & & & \\
\hline 8 & $\begin{array}{l}\text { Desenvolvedor de } \\
\text { pessoas }\end{array}$ & & & & & \\
\hline 9 & $\begin{array}{l}\text { Dimensionamento } \\
\text { do tempo }\end{array}$ & & & & & \\
\hline 10 & Foco no resultado & & & & & \\
\hline 11 & $\begin{array}{l}\text { Habilidade } \\
\text { interpessoal }\end{array}$ & & & & & \\
\hline 12 & $\begin{array}{l}\text { Integração das } \\
\text { diversas áreas } \\
\text { funcionais }\end{array}$ & & & & & \\
\hline 13 & $\begin{array}{l}\text { Resolvedor de } \\
\text { problemas }\end{array}$ & & & & & \\
\hline 14 & \begin{tabular}{|l|} 
Capacidade \\
para tratar com \\
culturas diversas
\end{tabular} & & & & & \\
\hline 15 & \begin{tabular}{|l|} 
Capacidade \\
de correlação \\
de fatos com \\
repercussões para \\
a empresa \\
\end{tabular} & & & & & \\
\hline 16 & $\begin{array}{l}\text { Antecipação } \\
\text { de ameaças e } \\
\text { oportunidades }\end{array}$ & & & & & \\
\hline 17 & Visão estratégica & & & & & \\
\hline
\end{tabular}

Fonte: Sousa e outros (2010), Sousa (2011), Echeveste e outros (1999).

Do grupo de competências listado por Echeveste e colaboradores (1999), algumas não puderam ser relacionadas aos parâmetros propostos acima, tais quais: gerenciamento da inovação, capacidade de viabilizar/implementar ideias e autoge- 
renciamento. Nos três casos, não foi possível traçar um paralelo entre as competências e a definição dos grupos. Procedeu-se, também, a relação com as competências preconizadas pelas DCN, citadas anteriormente. Em quatro delas, não foi possível estabelecer uma relação direta, ou seja, o texto não fazia referência às competências, a saber: capacidade para tratar com culturas diversas, dimensionamento do tempo, capacidade de delegação e agilidade.

Assim, para que fosse possível fazer a análise das competências a partir da leitura e interpretação das ementas, foram definidas palavras-chave, descritas no Quadro 2.

\section{Quadro 2 - Palavras-chave definidas para análise de conteúdo.}

\begin{tabular}{|c|c|c|}
\hline & Competência & Palavra-chave \\
\hline 1 & Administrador de conflito & $\begin{array}{l}\text { conflito, conflitos, conflituoso, conflituosa, con- } \\
\text { flitante }\end{array}$ \\
\hline 2 & Agilidade & agilidade, rapidez, velocidade \\
\hline 3 & Capacidade de decisão & decisão, decisões, decidir, decidido \\
\hline 4 & Capacidade de delegação & delegar, delegado, delegações \\
\hline 5 & Capacidade de liderança & liderança, líder, líderes \\
\hline 6 & Capacidade de negociação & negociação, negociar, negociado \\
\hline 7 & Coordenação de trabalho em equipe & trabalho em equipe, equipe, grupo, time \\
\hline 8 & Desenvolvedor de pessoas & treinamento, desenvolvimento, pessoas \\
\hline 9 & Dimensionamento do tempo & tempo, cronograma, planejamento \\
\hline 10 & Foco no resultado & resultado, resultados \\
\hline 11 & Habilidade Interpessoal & pessoal, individual, entre pessoas \\
\hline 12 & $\begin{array}{l}\text { Integração das diversas áreas funcio- } \\
\text { nais }\end{array}$ & $\begin{array}{l}\text { integração, integrado, diferentes áreas, funcio- } \\
\text { nais, departamentos }\end{array}$ \\
\hline 13 & Resolvedor de problemas & $\begin{array}{l}\text { problema, problemas, resolvedor, solução, solu- } \\
\text { cionar, solucionador }\end{array}$ \\
\hline 14 & $\begin{array}{l}\text { Capacidade para tratar com culturas } \\
\text { diversas }\end{array}$ & cultura, intercultural, diversidade \\
\hline 15 & $\begin{array}{l}\text { Capacidade de correlação de fatos } \\
\text { com repercussões para a empresa }\end{array}$ & $\begin{array}{l}\text { correlação, meio ambiente, terceiro setor, gover- } \\
\text { nos, responsabilidade social corporativa, mídia } \\
(*)\end{array}$ \\
\hline 16 & $\begin{array}{l}\text { Antecipação de ameaças e oportuni- } \\
\text { dades }\end{array}$ & $\begin{array}{l}\text { ameaça, ameaças, oportunidade, oportunidades, } \\
\text { risco, riscos }\end{array}$ \\
\hline 17 & Visão estratégica & estratégia, estratégico, estratégica, estrategista \\
\hline
\end{tabular}

Fonte: Brasil (2005) e referencial teórico.

Nota: $\left.{ }^{*}\right)$ embora essas palavras não sejam semanticamente relacionadas à competência, é disso que ela trata diretamente. Por isso foi feita a opção por utilizar essas expressões, neste caso.

Além das 17 competências listadas acima, optou-se também pela busca de palavras-chave que indicassem, nas ementas das disciplinas, conteúdos ligados à gestão internacional. Foi criada uma categoria denominada trânsito em negócios internacionais, para a qual foram atribuídas as palavras internacional, internacionais, global, globais e globalização. Embora não coincida exatamente com uma das competências que resultaram da literatura (ECHEVESTE et al., 1999) e das decisões demonstradas anteriormente, considerou-se importante fazer essa análise para identificar, nos cursos, quais conteúdos seriam mais específicos para a formação do gestor que pretende atuar em contexto internacional. 
Foram analisadas as ementas dos cursos: (1) que apresentavam conceito igual a cinco na avaliação de cursos de graduação brasileiros, considerando-se tanto o conceito do ENADE, quanto a avaliação in loco feita pelas comissões de especialistas do MEC, divulgado em janeiro de 2011 ; (2) cujas IES faziam parte do projeto de pesquisa Pró-Administração ligados à UFU. Optou-se por acrescentar o segundo critério devido ao fato de o estudo ter sido desenvolvido como parte desse projeto de pesquisa, em alinhamento com as linhas de pesquisa de seu programa de pós-graduação em Administração.

Foram analisadas as ementas disponibilizadas pelas seguintes instituições: Escola de Governo Professor Paulo Neves de Carvalho (EG), Faculdade de Economia e Finanças do Instituto Brasileiro de Mercado de Capitais (IBMEC), Centro Universitário Álvares Penteado da Fundação Escola de Comercio Álvares Penteado (FECAP), Escola de Administração de Empresas de São Paulo (FGV-EAESP), Instituto de Ensino e Pesquisa (INSPER), Instituto Superior Tupy (IST), Fundação Universidade do Estado de Santa Catarina (UDESC), Universidade Federal Fluminense (UFF), Universidade Federal de Goiás (UFG), Universidade Federal de Juiz de Fora (UFJF), Universidade Federal de Lavras (UFLA), Universidade Federal de Minas Gerais (UFMG), Universidade Federal de Mato Grosso do Sul (UFMS), Universidade Federal do Paraná (UFPR), Universidade Federal do Rio Grande do Sul (UFRGS), Universidade Federal de Santa Catarina (UFSC), Universidade Federal de São João Del Rei (UFSJ), Universidade Federal de Santa Maria (UFSM), Universidade Federal de Uberlândia (UFU), Fundação Universidade Federal de Viçosa (UFV), Universidade Estadual Paulista Júlio de Mesquita Filho (UNESP), Universidade Federal de Itajubá (UNIFEI) e Faculdade Novos Horizontes (UNIHORIZONTES).

Os materiais foram coletados após consulta aos websites das IES ou contatos feitos por e-mail. Buscaram-se, inicialmente, os projetos pedagógicos, os programas, a descrição dos cursos e as ementas. A opção por analisar apenas as ementas foi feita ao se constatar que, entre os materiais disponibilizados pelas IES, apenas esse documento é tornado público pela maioria. Nota-se que apenas quatro cursos divulgavam seu projeto pedagógico. Foi feita uma tentativa de acesso, sem sucesso, a esses documentos via e-mail e contato telefônico.

Assim, a unidade de análise foi composta pelas ementas de cada disciplina oferecida pelos 24 cursos acessados. Procedeu-se, então, à análise de conteúdo clássica, por meio da leitura e identificação de palavras-chave, conforme processo descrito a seguir.

Anailise dos dlados

A análise de conteúdo foi estruturada em três etapas. Inicialmente, o texto correspondente à ementa de cada disciplina foi transcrito para o programa Excel, do qual se originou um arquivo específico para cada um dos 24 cursos.

Em seguida, procedeu-se a uma busca simples pelas palavras-chave (quadro 2) com a utilização do localizador de palavras automático do programa. Para cada competência descrita no quadro 1 foi atribuída uma cor, usada para marcar a célula onde era encontrada uma das palavras dentro do texto que descrevia a ementa de cada disciplina.

Quando uma segunda palavra-chave, de outra competência, era encontrada dentro da mesma ementa, era feita uma nova marcação com cor diferente em célula ao lado da primeira, e assim sucessivamente. Após as definições necessárias ao programa, esse processo foi desenvolvido automaticamente pelo Excel para todos os 24 cursos. Selecionaram-se, assim, as ementas em que havia alguma relação com as competências identificadas. Em um segundo momento, procedeu-se a uma verificação mais apurada.

Essa segunda etapa consistiu na leitura de todas as células que não foram marcadas por nenhuma cor, para identificar se havia alguma aderência aos conteúdos por meio de outras expressões que pudessem ter deixado de ser contempladas no quadro 2. Em seguida, eliminaram-se as células que, efetivamente, não tinham qualquer ade- 
rência aos parâmetros estabelecidos. Dessa leitura criteriosa, resultaram as ementas que foram analisadas, cujos resultados estão descritos adiante.

Finalmente, todas as ementas foram relidas e classificadas de acordo com as cores atribuídas a cada uma das competências. Construiu-se, então, uma matriz para cada um dos 24 cursos, relacionando-se cada disciplina com as competências. O resultado permitiu enxergar, de maneira inferencial , a identificação e a frequência com que as competências se refletiriam nas ementas das disciplinas. Posteriormente, os quadros foram analisados conjuntamente a fim de se delinear um mapa referente a estes programas, conforme os resultados que se discutem a seguir.

\section{Apreserntação dlos Resrritados}

Nos 24 cursos estudados, foram identificadas 1.324 disciplinas com suas respectivas ementas. Foram consideradas tanto as disciplinas obrigatórias quanto as optativas, razão pela qual a média das disciplinas identificadas foi de 55 por curso. 0 menor número de disciplinas identificado em um curso foram 30, enquanto o maior chegou a 97. As 622 ementas analisadas correspondem a 46,97\% do corpus identificado inicialmente.

A seguir, apresenta-se a discussão dos resultados consolidados e, posteriormente, as análises relacionadas aos grupos identificados nos estudos que serviram de base para a definição do parâmetro de análise.

Vis a

O Gráfico 1 reflete a visão geral sobre a quantidade de competências identificadas. Optou-se por trabalhar com números absolutos porque uma mesma ementa podia conter mais de uma competência.

\section{Gráfico 1 - Quantidade total de competências identificadas nas ementas}

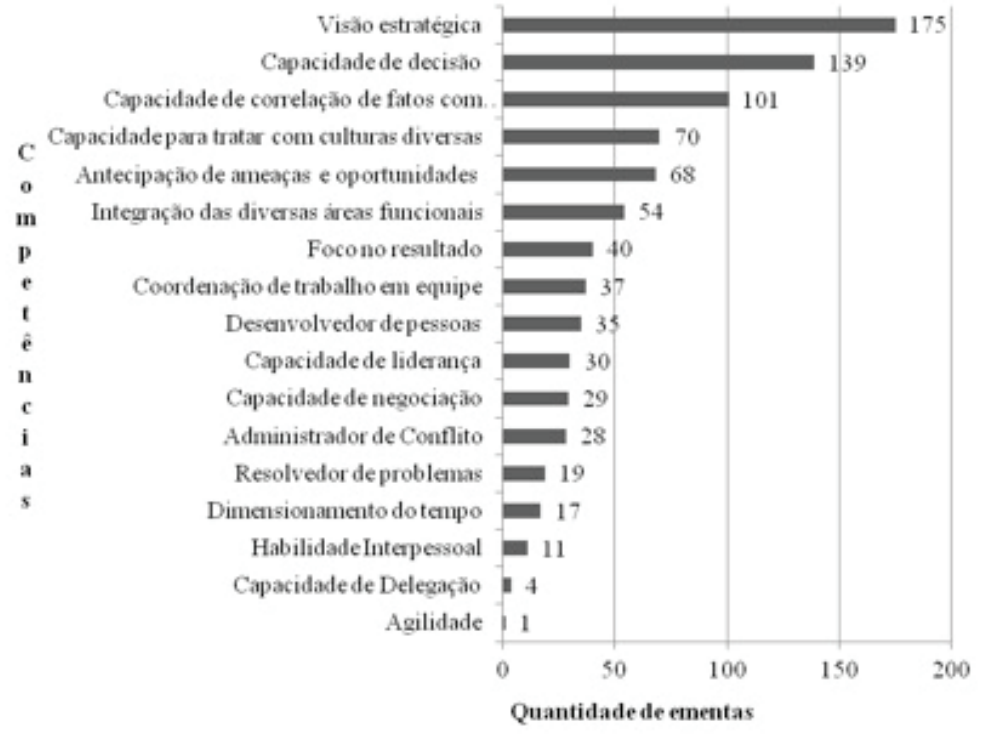

Fonte: Dados da pesquisa.

Observa-se que, entre as ementas analisadas, a maior ocorrência foi da competência visão estratégica, presente em $28,13 \%$ delas. Além de Echeveste e colaboradores (1999), essa característica também é indicada por Gondin e outros (2009) e Fleury 
e Fleury (2001). A palavra estratégia aparece também como parte do conteúdo que o egresso deve aprender na faculdade, entre os conteúdos de formação profissional contemplados nas DCN. Pensar estrategicamente é uma das primeiras competências delineadas pelas diretrizes para a formação do futuro administrador.

Capacidade de decisão aparece em segundo lugar, tendo sido identificada em 139 das disciplinas analisadas (22,34\% do total), e também está presente na primeira competência que os egressos devem desenvolver, de acordo com as DCN e nas discussões de Le Boterf (2003). Pode-se dizer que os resultados acima não surpreendem, uma vez que as duas competências estão explícitas nas DCN delineadas para direcionar os conteúdos dos cursos de Administração.

A competência capacidade de correlação de fatos com repercussão para a empresa aparece em terceiro lugar, presente em 16,23\% das ementas. É apontada como importante por Black e Gregersen (1999). Encontra-se também nas recomendações das competências que deveriam ser desenvolvidas nos discentes dos cursos de Administração, segundo as DCN. Os cursos analisados trabalham a correlação de dados estatísticos, mas não necessariamente aquela que trata da relação entre fatos externos ou acontecimentos internos que possam, de maneira efetiva, afetar a gestão dos negócios (por exemplo, ligadas a aspectos ambientais, sociais ou políticos).

A categoria trânsito em negócios internacionais, criada para avaliar disciplinas específicas sobre gestão internacional, globalização ou comércio exterior apresenta $15,11 \%$ das ementas analisadas, contemplando 94 disciplinas. A busca de conhecimento específico nesse campo é apontada por McCall e Hollenbeck (2003) como parte importante das lições aprendidas pelos gestores globais.

Na sequência, ocupando a quarta posição entre as competências, aparece a capacidade para tratar com culturas diversas, com $11,25 \%$ das ementas analisadas. Ela é apontada pela maioria dos autores estudados como fundamental ao sucesso do gestor em contexto global. (BLACK; GREGERSEN, 1999; FISCHER et at., 2009; GONDIN et al., 2009; HOMEM; DELLAGNELLO, 2006; LESSA et al., 2008; MCCALL; HOLLENBECK, 2003;SEBBEN, 2009) Essa competência não se encontra refletida naquelas a serem desenvolvidas junt aos egressos do curso de Administração, de acordo com as DCN.

Vale ressaltar que a competência capacidade para tratar com culturas diversas foi identificada em 70 das ementas analisadas, cerca de metade das 139 encontradas em capacidade de decisão. A competência visão estratégica, por sua vez, apareceu 2,5 vezes mais que a relacionada aos aspectos interculturais. Esse resultado poderia indicar que os cursos de Administração nacionais aqui analisados ainda não trabalhariam de maneira específica a importância da cultura para o contexto da internacionalização.

Em resumo, destaca-se que as cinco competências identificadas em um maior número de ementas, de acordo com os parâmetros propostos, foram: visão estratégica, capacidade de decisão, capacidade de correlação de fatos com importância para a empresa, trânsito em negócios internacionais e capacidade para tratar com culturas diversas. Ressalta-se que, embora essa última tenha relação direta com o trabalho de um gestor no contexto internacional, ela apresenta um número menor de ementas que as outras, o que indica espaço para que alguns conteúdos possam ser repensados diante de mudanças sociais e da necessidade crescente de mobilidade. (SEBBEN, 2009)

Com relação às competências que encontraram menor incidência nas ementas analisadas, agilidade foi identificada em apenas uma disciplina (Administração da Produção I, da UFJF), embora faça parte das características listadas por Echeveste e outros (1999), corroborada por Homem e Dellagnelo (2006) e Hoelchlin (1995, apud LESSA et al., 2008). Uma das possíveis razões para esta baixa incidência pode ser o fato dela ser considerada uma competência tácita, difícil de ser desenvolvida no contexto acadêmico. Le Boterf (2003) trata em seus estudos da importância do profissional em desenvolver a habilidade de fazer escolhas em situações de urgência. A competência também não encontra paralelo entre as DCN.

Capacidade de delegação $(0,64 \%)$, habilidade interpessoal $(1,76 \%)$ e dimensionamento do tempo $(2,73 \%)$ também tiveram baixa incidência. As duas primeiras são citadas por Hoelchlin (1995, apud LESSA et al., 2008); McCall e Hollenbeck (2003) e Homem e Dellagnello (2006). Cheetham e Chivers (1998) apontam para a questão 
da administração do tempo. Três das quatro características que obtiveram menor incidência entre as ementas analisadas não estão contempladas entre as competências e habilidades necessárias ao futuro administrador previstas nas DCN: capacidade de delegação, dimensionamento do tempo e agilidade.

Em linhas gerais, percebe-se que as competências visão estratégica e capacidade para tomar decisões são desenvolvidas pelos cursos, em aderência ao que preconizam as DCN. São, todavia, características que qualquer gestor, independentemente de localização geográfica, precisa desenvolver. Em se tratando das competências necessárias à atuação do gestor brasileiro no exterior, as disciplinas trabalham moderadamente as habilidades voltadas à diversidade cultural. No que diz respeito ao desenvolvimento de pessoas, liderança e gestão de equipes, existe espaço para reflexão, considerando-se o baixo número de disciplinas que discutem esse aspecto.

\section{Visäo dlas comperências de acordo com os grupos resulturntes do} levantanento

Após identificar as competências em cada ementa das disciplinas analisadas, proceder ao somatório e identificar as frequências, voltou-se aos parâmetros propostos no quadro 1 . O objetivo, nessa etapa, foi avaliar a totalização de disciplinas em que se verificou aderência às competências, de acordo com o que se contabilizou em cada grupo decorrente da análise fatorial do levantamento junto aos gestores brasileiros no exterior. (SOUSA, 2011) O resultado encontra-se no Gráfico 2.

\section{Gráfico 2 - Ementas identificadas em cada grupo}

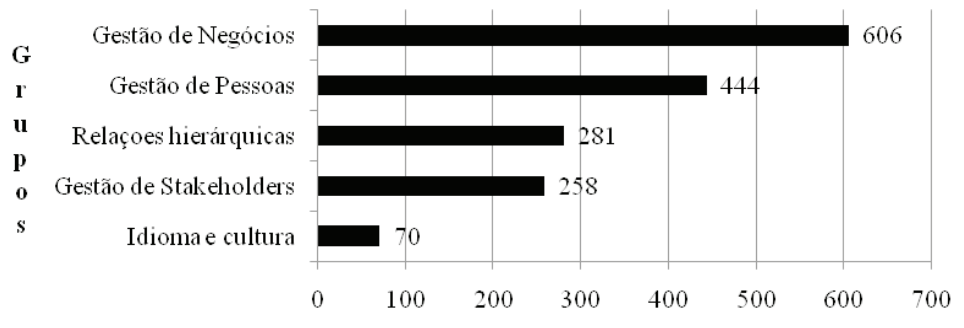

Quantidade de ementas

Fonte: Dados da pesquisa.

No caso da variável gestão de negócios, ela aparece em primeiro lugar, totalizando 606 ementas. As principais competências identificadas para esse grupo foram: visão estratégica, presente em $28,13 \%$ das ementas; capacidade de decisão, presente em $22,34 \%$ e capacidade de correlação de fatos com repercussão para a empresa, com $16,23 \%$. Tratam-se igualmente das três competências mais identificadas na avaliação geral apresentada no Gráfico 1. Visão estratégica aparece em primeiro lugar como a competência mais presente em 15 dos 24 cursos analisados. Capacidade de decisão e capacidade de correlação de fatos com repercussão para a empresa emergem como as competência mais presentes em oito cursos. Pode-se inferir também que o principal foco dos cursos analisados, a partir deste estudo, é o desenvolvimento das competências que vão dar suporte para que o gestor seja capaz de pensar e decidir de maneira estratégica, levando em consideração os fatos - internos ou externos - que possam ter algum tipo de repercussão para a empresa. A competência capacidade de negociação pode ser identificada em 29 disciplinas entre os 24 cursos. Foi o número mais baixo encontrado nesse grupo. Ela é citada como característica importante do gestor global pelos autores Black e Gregersen (1999) e Le Boterf (2003). Pode-se dizer que os cursos analisados possuem foco razoável em seu desenvolvimento, o que não causa estranhamento e está alinhado às premissas das DCN para os cursos 
de Administração. Por outro lado, pode haver uma oportunidade de melhoria no que diz respeito à capacidade de negociação.

Já em relação à variável gestão de pessoas, foram identificadas 444 ementas lideradas pelas competências capacidade de decisão (22,34\% das ementas) e integração entre as diversas áreas funcionais $(8,68 \%)$. Observa-se a intensa presença da primeira competência, que aparece 2,5 vezes mais que a segunda. Interessante também o fato de competências como coordenação de trabalho em equipe, desenvolvedor de pessoas, capacidade de liderança e administrador de conflitos, inerentes aos processos de gestão de pessoas, terem ocupado respectivamente a quarta, quinta, sexta e oitava colocação no que diz respeito à quantidade de ementas identificadas. Isso pode indicar a oportunidade para um olhar mais crítico em relação às competências que cada curso pretende desenvolver em seus egressos. Reforça ainda o que disse Sebben (2009) acerca das competências comportamentais. Parcialmente, esses resultados apresentam indícios acerca da necessidade de os cursos de Administração estarem em constante mudança, acompanhando o que acontece na sociedade, visto que se trata de uma ciência viva. Em uma linha contrária, pode-se também retomar as críticas de Nicolini (2002) acerca da universidade estar unicamente a serviço do mercado.

Quanto a relações hierárquicas, foram identificadas 281 ementas, mais uma vez reforçando-se que uma mesma disciplina poderia conter diferentes competências. 0 principal indicador foi capacidade para lidar com culturas diversas $(11,25 \%)$, seguido por integração das diversas áreas funcionais $(8,68 \%)$. Mais uma vez, percebe-se coerência entre os elementos colocados para análise. O resultado corrobora a definição de Lyles (2001) acerca de expatriados serem veículos para aquisição de conhecimentos. Também vai ao encontro do estudo de Closs e Antonello (2008), segundo o qual o processo de aprendizagem acontece na interação entre indivíduos. Por outro lado, as competências administrador de conflito $(4,5 \%)$, resolvedor de problemas $(3,05 \%)$ e habilidade interpessoal $(1,76 \%)$ aparecem na base da relação com a menor quantidade de disciplinas identificadas. A gestão dos relacionamentos hierárquicos, em especial em diferentes culturas, irá passar necessariamente por essas competências, com ênfase para a capacidade de gerenciar os conflitos que poderão surgir das próprias dificuldades culturais inerentes ao processo de gestão internacional. Parece haver espaço para intensificar o desenvolvimento dessas competências, com vistas a reforçar o arsenal de habilidades que poderá ser necessário ao gestor que assumir designações internacionais.

No que tange a gestão de stakeholders, foram 258 ementas identificadas. A competência presente no maior número de disciplinas foi capacidade de correlação de fatos com repercussões para a empresa (16,23\%). Interessante observar que muitas das disciplinas que entraram nesse grupo referem-se à capacidade estatística de estabelecer correlações matemáticas (aspecto racional), e outras ligadas à responsabilidade social corporativa e que exercem impacto sobre a imagem da organização (aspecto relacional). De acordo com Dutra (2004), é por meio das competências que os indivíduos são capazes de entregar resultados esperados pela organização ou pelos públicos de interesse. Foco no resultado ficou em segundo lugar $(6,43 \%$ das disciplinas analisadas), tem menos da metade das disciplinas da competência que lidera o grupo. Isso pode indicar a existência de espaço para reflexão sobre a interação com os públicos com os quais a empresa se relaciona, lembrando que os resultados de uma organização não se prendem unicamente ao lucro, mas também aos impactos positivos ou negativos - que ela é capaz de gerar para seus diferentes stakeholders. Muitas disciplinas presentes nesse grupo relacionavam-se aos resultados financeiros (contabilidade), o que poderia indicar que os cursos de Administração relativos a esse corpus deveriam avançar no estudo dos demais resultados que compõem o conceito de sustentabilidade (ambientais e sociais).

$\mathrm{Na}$ base da lista, aparecem as competências administrador de conflitos (4,5\%), resolvedor de problemas $(3,05 \%)$ e habilidade interpessoal $(1,76 \%)$. Todas são importantes no relacionamento com sindicatos, governos e mídia, tanto no contexto nacional quanto internacional. Observou-se que existem disciplinas que tratam do entendimento dos impactos do governo em relação aos negócios, em especial sob o 
aspecto da questão tributária, bem como disciplinas ligadas à relações trabalhistas e sindicais. Por outro lado, não foi constatada a existência de nenhuma disciplina que prepare o gestor para se relacionar com a mídia, mesmo entre aquelas denominadas comunicação empresarial. Essas competências incluem-se ainda no que Sebben (2009) denomina de comportamentais, que enfatizam a importância dos relacionamentos para o processo de gestão. Fischer e outros (2009) abordam a importância de se estabelecer diálogos para minimizar diferenças. Cheetam e Chivers (1998), em sua classificação acerca das competências profissionais, também usam o termo comportamental ou pessoal para se referir ao relacionamento social e intrapessoal.

Por fim, no que diz respeito a Idioma e Cultura, foram identificadas 70 ementas dentro de uma única competência: capacidade para tratar com culturas diversas $(11,25 \%)$. Trata-se do único grupo em que esse tema foi registrado. Closs e Antonello (2008) ressaltam que os processos de aprendizagem, sejam individuais ou gerenciais, envolvem indivíduos diferentes, marcados profundamente pelas estruturas onde se desenvolveram pessoal, intelectual e profissionalmente. Essa baixa incidência é contrária ao que Fischer e colaboradores (2009) denominam de competência intercultural. A importância de entender e gostar de relacionar-se em culturas diferentes também é apontada nos estudos de Sebben (2009).

Embora dispersa em 70 disciplinas dos 24 cursos, a competência capacidade para tratar com culturas diversas poderia ser melhor desenvolvida, independente da vocação do curso ser local, regional ou nacional. Isso porque a mobilidade é uma realidade no mercado de trabalho e, mesmo dentro do Brasil, as diferenças culturais são grandes entre os estados do Sul, Sudeste, Nordeste, Norte e Centro Oeste. No que diz respeito ao ensino de idiomas, foram identificadas apenas nove disciplinas. Considerando-se a formação de gestores aptos a atuar no contexto global, a necessidade, tanto do conhecimento de idiomas quanto de disciplinas relacionadas à cultura, pode ser de grande valia para os egressos dos cursos de Administração.

A leitura de cada grupo permite inferir que os programas analisados possibilitam ao egresso certo grau de desenvolvimento de competências necessárias para quem pretende trabalhar no exterior. A formação oferecida é abrangente, mas não se identifica uma preocupação com aspectos relativos à diversidade cultural diretamente relacionada ao gestor global.

\section{Comsidleratçoes Finais}

A análise dos resultados permite identificar que, entre os cursos de Administração que fizeram parte do estudo, existe, parcialmente, aderência às competências que o profissional interessado em seguir carreira no exterior precisaria desenvolver. Elas se encontram dispersas em diferentes disciplinas, com maior ênfase para aquelas voltadas ao estabelecimento de estratégias e tomada de decisões. Nesse sentido, existe um alinhamento com as DCN estabelecidas para a formação de administradores no Brasil.

Observou-se ainda a oportunidade no que diz respeito à inserção de conteúdos especificamente voltados para a gestão multicultural e o estabelecimento de relacionamentos entre o ambiente interno e externo. Aparentemente, embora exista uma crescente necessidade de mobilidade entre as organizações, os cursos analisados parecem não estar especificamente voltados para o atendimento a essas demandas.

Este estudo teve como unidade de análise as ementas das disciplinas estudadas em cursos de Administração. Sabe-se que as competências são formadas a partir de uma somatória de fatores, entre eles, a sala de aula. Os diferentes conteúdos acadêmicos, em suas vertentes teóricas e práticas, irão compor parte de um arcabouço ao qual irão somar-se conhecimentos adquiridos por meio de aulas, leituras, situações vividas no mercado de trabalho e troca de experiências. A disciplina em si poderá conter parte dos conhecimentos necessários ao desenvolvimento de competências, visto que, de acordo com os conceitos mais aceitos sobre o tema, competências combinam conhecimentos, habilidade e atitudes. 
Quando o tema é a construção de competências, parece possível afirmar que elas se constroem ao longo das diversas experiências pelas quais passamos durante a nossa vida. Isso indica que, muitas vezes, no contexto da vida acadêmica, o aprendizado de determinada competência deixa de ser relacionado a um aspecto específico da vida profissional - como no caso das designações internacionais - simplesmente porque ainda não se chegou a esse momento no qual a competência se traduz em uma situação real de trabalho. No entanto, é fundamental buscarmos respostas a essa associação entre a formação e mundo do trabalho.

A análise das ementas das disciplinas dos cursos brasileiros de graduação em Administração escolhidos para este estudo indicou que, direta ou indiretamente, uma parte das competências necessárias à ação do gestor global - identificadas no levantamento feito junto a profissionais brasileiros que trabalham no exterior - parece estar sendo contemplada. Essa constatação aponta que tanto as DCN quanto o planejamento curricular desses cursos estejam na direção correta, no entanto, alerta para a necessidade de um olhar mais cuidadoso para temas como gestão de stakeholders, idiomas e cultura.

Existe certa uniformidade entre as competências mais frequentes em cada ementa, considerando-se a análise de cada curso. Na maioria deles, uma destas três competências aparece em primeiro lugar: visão estratégica, capacidade de decisão e capacidade de correlação de fatos com repercussão para as empresas. De um lado, esse resultado coincide com a própria apresentação dos resultados gerais, resumida no Gráfico 1. Por outro lado, entre as competências que registraram menor frequência (as três últimas), ocorre uma dispersão entre os cursos, não sendo possível identificar uma predominância tão nítida quanto as disciplinas que ocupam o topo da relação. As que aparecem na base da lista mais vezes são: agilidade, coordenação de trabalho em equipe, capacidade de delegação, capacidade de negociação, desenvolvedor de pessoas, habilidade interpessoal e capacidade de administrar conflitos.

Em 27,33\% das ementas, identificaram-se duas competências também variáveis ao longo das 170 disciplinas com essa característica. Apenas uma disciplina, considerada isoladamente, contemplou seis competências (número máximo): Comportamento Organizacional, oferecida no curso de Administração da UFG (campus Goiânia). São elas: administrador de conflito, capacidade de liderança, capacidade de negociação, coordenação de trabalho em equipe, habilidade interpessoal e capacidade para tratar com culturas diversas. Uma pequena amostra de 0,64\% das ementas analisadas permitiu a identificação de cinco competências em uma mesma disciplina.

Esse resultado demonstra que na maioria das disciplinas estudadas foi possível verificar a aderência de pelo menos uma competência por disciplina, enquanto a presença de um número maior foi mais difícil de ser constatada. Isso pode indicar uma dificuldade de trabalhar conteúdos de forma interdisciplinar e transdisciplinar.

Em parte, pode ser que esse resultado esteja alinhado também às exigências das DCN, que especificam quais competências devem ser desenvolvidas. Elas indicam um comportamento isomórfico baseado em exigências normativas e ressalta um paradoxo: de um lado, somos forçados a estabelecer diferenças e construir competências, que neste estudo se voltam aos questionamentos da formação de gestores internacionais, mas de outro, todos adotam o mesmo comportamento direcionado por órgãos de controle.

Contudo, por delimitação, pode ser que a redação das ementas não tenha efetivamente a responsabilidade de refletir de maneira específica como se dará o desenvolvimento das competências, ficando isso a cargo de programas mais detalhados, do plano de aula e da relação entre professor e aluno em sala de aula. A dificuldade em se ter acesso a esses dados é um dos fatores limitadores desta pesquisa, uma vez que existe a possibilidade de terem sido analisados conteúdos desatualizados ou parcialmente disponibilizados pelos websites institucionais, principal fonte para coleta utilizada. Pode ser também apontado como limite a dificuldade de referencial atualizado que relacionasse o tema desenvolvimento de competências e o campo da gestão internacional. Embora tenha sido produzido há 12 anos, o estudo de Echeveste e outros (1999) foi selecionado pela aderência aos objetivos deste artigo. 
Entre as indicações para estudos futuros, sugere-se a busca de informações que possam ser extraídas dos projetos pedagógicos, a fim de se proceder a um estudo mais detalhado. Entrevistas com professores e egressos também podem tornar as análises mais robustas, em especial, aqueles profissionais com vivência no exterior.

Referêncials

BARTLETT, C. A.; GHOSHAL, S. Gerenciando empresas no exterior: a solução transnacional. São Paulo: Makron Books, 1992.

BASTOS, F. C.; MONTEIRO JÚNIOR, J. G. Formação de administradores: um estudo sobre competências docentes na ótica de alunos e professores. In: ENCONTRO DE ENSINO E PESQUISA EM ADMINISTRAÇÃO E CONTABILIDADE, 2., 2009, Curitiba. Anais... Rio de Janeiro: Associação Nacional de Pós-Graduação e Pesquisa em Administração, 2009. 1 CD Rom.

BAUER, M. W.; GASKELL, G. (Ed.). Pesquisa qualitativa com texto, imagem e som: um manual prático. Petrópolis: Vozes, 2002.

BLACK, J. S.; GREGERSEN, H. B. The right way to manage expats. Harvard Business Review, v. 77, n. 2, 1999.

; MENDENHALL, M.; ODDOU, G. Toward a comprehensive model of international adjustment: an integration of multiple theoretical perspectives. Academy of Management Review, v. 16, n. 2, p. 291-317, 1991.

BRASIL. Ministério da Educação e Cultura. Conselho Nacional de Educação Câmara de Educação Superior. Resolução no 1, de $1^{\circ}$ de fevereiro de 2005.

Estabelece normas para o apostilamento, em diplomas de cursos de graduação em Pedagogia, do direito ao exercício do magistério nos quatro anos iniciais do Ensino Fundamental. Disponível em: <http://portal.mec.gov.br/cne/arquivos/pdf/ rces001_05.pdf>. Acesso em: 29 jul. 2010.

BRITO, M. R. O SINAES e o ENADE: da concepção à implantação. Revista Avaliação, Campinas / Sorocaba, v. 13, n. 3, p. 841-850, 2008.

BROOKFIELD GLOBAL RELOCATION SERVICE. Global relocation trends - 2010

Survey Report. Estados Unidos, 2010. Disponível em <http://www.brookfieldgrs. com> Acesso em: 7 jun. 2010.

BUENO, J. M.; DOMINGUES, C. R.; DEL CORSO, J. M. O processo de expatriação na integração de culturas: o caso Renault do Brasil. In: ENCONTRO DA ANPAD, 28., 2004, Curitiba. Anais... Rio de Janeiro: ANPAD, 2004. 1 CD-ROM.

CALIGIURI, P.; DI SANTO, V. Global competence: what is, and can it be developed trough global assignments? Human Resource Planning, v. 24, n. 3, 2001.

CHEETAM, G.; CHIVERS, G. The reflective (and competent) practitioner: a model of professional competence which seeks to harmonise the reflective practitioner and competence-based approaches. Journal of European Industrial Training, v. 22, n. 7, p. 267-276, 1998.

CLOSS, L. Q.; ANTONELLO, C. S. O uso do método de história de vida para compreensão dos processos de aprendizagem gerencial. In: ENCONTRO DA ANPAD, 32., 2008, Rio de Janeiro. Anais... Rio de Janeiro: ANPAD, 2008. 1 CD-ROM.

DELUIZ, D. A globalização econômica e os desafios à formação profissional. Boletim Técnico do Senac, v. 30, n.3. set./dez. 2004. Disponível em: <http://www.senac. br/BTS/303/boltec303f.htm>. Acesso em: 14 Mar. 2011.

DUTRA, J. S. Competências: conceitos e instrumentos para a gestão de pessoas na empresa moderna. São Paulo: Editora Atlas S/A, 2004. 
ECHEVESTE, S. et al. Perfil do executivo no mercado globalizado. Revista de Administração Contemporânea, Curitiba, PR, v. 3, n. 2, p. 167-186, maio/ago. 1999.

FISCHER et al. Competências na gestão intercultural: desafios para a aprendizagem e qualificação. In: ENCONTRO DA ANPAD, 33., 2009, São Paulo. Anais... Rio de Janeiro: ANPAD, 2009, 1 CD-ROM.

FLEURY, M. T. L.; FLEURY, A. Desenvolver competências e gerir conhecimentos em diferentes arranjos empresariais: o caso da indústria brasileira de plástico. In: FLEURY, M. T. L.; OLIVEIRA, J. M. M. Gestão estratégica do conhecimento: integrando aprendizagem, conhecimento e competência. São Paulo: Atlas, 2001. p. $189-211$.

FUNDAÇÃO DOM CABRAL. Ranking transnacionais brasileiras 2009. Belo Horizonte, 2010. Disponível em: <http://www.fdc.org.br/pt/Documents/ranking_ transnacionais_2009.pdf>. Acesso em: 19 jan. 2010.

GONDIM, S. M. G. et al. Trajetórias de gestores internacionais: em busca de subsídios para políticas de formação e desenvolvimento de gestores. In: ENCONTRO DA ANPAD, 33., 2009, São Paulo. Anais... Rio de Janeiro: ANPAD, 2009. 1 CD-ROM.

HOMEM, I. D.; DELLAGNELLO, E. H. L. Novas formas organizacionais e desafios para os expatriados. Revista de Administração de Empresas, São Paulo, v. 5, n. 1, jan./ jun. 2006. Disponível em: <http://rae.fgv.br/rae-eletronica/vol5-num1-2006/novasformas-organizacionais-desafios-para-expatriados>. Acesso em: 16 Jan. 2010.

JOLLY, A. Alteridade: ser executivo no exterior. In: CHANLAT, J. F. O indivíduo nas organizações: dimensões esquecidas. 3. ed. São Paulo: Atlas, 1996. p. 83-124.

KANTER, R. M. Classe mundial: uma agenda para gerenciar os desafios globais em benefício das empresas e das comunidades. Rio de Janeiro: Campus, 1996.

LE BOTERF, G. Desenvolvendo a competência dos profissionais. Porto Alegre: Artmed, 2003.

LESSA, L. C. C. et al. Executivos brasileiros expatriados: percepções da nova função e influência da distância psíquica. In: ENCONTRO DA ANPAD, 32., 2008, Rio de Janeiro. Anais... Rio de Janeiro: ANPAD, 2008, 1 CD-ROM.

LYLES, M. A. Aprendizagem organizacional e transferência de conhecimento em joint ventures internacionais. In: FLEURY, M. T. L.; OLIVEIRA JUNIOR, M. M. Gestão estratégica do conhecimento: integrando aprendizagem, conhecimentos e competências. São Paulo: Atlas, 2001. p. 273-293.

MCCALL, M.; HOLLENBECK, G. Desenvolvimento de executivos globais: as lições da experiência internacional. Porto Alegre: Bookman, 2003.

MCCAUGHEY, D.; BRUNING, N. S. Enhancing opportunities for expatriate job satisfaction: HR strategies for foreign assignment sucess. Human Resource Planning, v. 28, n. 4, Out. 2005.

MINTZBERG, H.; GOSLING, J. Educando administradores além das fronteiras. Revista de Administração de Empresas, São Paulo, v. 43, n. 2, p. 29-43, abr./maio/ jun. 2003.

NICOLINI, A. O futuro administrador pela lente das novas Diretrizes Curriculares: cabeças "bem-feitas" ou "bem cheias"? In: ENCONTRO DA ANPAD, 26., 2002, Salvador. Anais... Rio de Janeiro: ANPAD, 2002, 1 CD-ROM.

Qual será o futuro das fábricas de administradores? Revista de Administração de Empresas, São Paulo, v. 43, n. 2, p. 44-54, abr./jun. 2003.

NUNES, S. C.; BARBOSA, A. C. Q. A inserção das competências no curso de graduação em administração: um estudo em universidades brasileiras. In: 
ENCONTRO DA ANPAD, 27., 2003, Atibaia. Anais... Rio de Janeiro: ANPAD, 2003, 1 CD-ROM.

ODERICH, C. L.; LOPES, F. D. Novas competências e gerência internacional: uma análise a partir da perspectiva institucional. REAd - Revista Eletrônica de Administração, Porto Alegre, Edição 19, v. 7, n. 1, jan./fev. 2001. Disponível em: <http://hdl.handle.net/10183/19459>. Acesso em: 16 mar. 2010.

PAIVA, K. C. M.; MELO, M. C. O. L. Competências, gestăo de competências e profissőes: perspectivas de pesquisas. Revista de Administração Contemporânea, Curitiba, v. 12, n. 2, p. 339-368. Abr-Jun 2008.

PEREIRA, N. A. F.; PIMENTEL, R.; KATO, H. T. Expatriação e estratégia internacional: o papel da família como fator de equilíbrio na adaptação do expatriado. In: ENCONTRO DA ANPAD, 28., 2004, Curitiba. Anais... Rio de Janeiro: ANPAD, 2004, 1 CD-ROM.

RAMOS, M. N. A pedagogia das competências: autonomia ou adaptação? São Paulo: Cortez, 2001.

RUAS, R. Gestão por competências: uma contribuição à estratégia das organizações. In: RUAS, R. L.; ANTONELLO, C. S.; BOFF, L. H. Aprendizagem organizacional e competências. Porto Alegre: Bookman, 2005. p. 34-54.

SEBBEN, A. Expatriados.com: um desafio para os RHs interculturais. Porto Alegre: Artes e Ofícios, 2009.

SELMER, J. Who wants an expatriate business career? In search of the cosmopolitan manager. International Journal of Cultural Management, v. 1, n. 173, p. 173-184, 2001.

SOCIEDADE BRASILEIRA DE ESTUDOS DE EMPRESAS TRANSNACIONAIS E DA GLOBALIZAÇÃO ECONÔMICA. Internacionalização das empresas brasileiras: estudo temático 2005 / 2006 do Fórum de Líderes / SOBEET. São Paulo: Clio Editora, 2007.

SOUSA, A. F. O gestor brasileiro no exterior: e a academia, acompanha essas competências? 2011. 167 f. Dissertação (Mestrado em Administração) - Faculdade de Gestão de Negócios da Universidade Federal de Uberlândia. Uberlândia, 2011.

SOUSA, A. F. et al. Gestores brasileiros que trabalham no exterior: um estudo baseado nas lições aprendidas por executivos globais. In: ENCONTRO DA ANPAD, 34., 2010, Rio de Janeiro. Anais... Rio de Janeiro: ANPAD, 2010, 1 CD-ROM.

TUNG, R. American expatriates abroad: from neophytes to cosmopolitans. Journal of World Business, v. 33, n. 2, p. 125-144, 1998.

ZARIFIAN, P. Objetivo competência: por uma nova lógica. São Paulo: Editora Atlas, 2008.

\section{Submissão: 4/1/2011}

Aprovação: 27/3/2013 